\title{
Comunicación

\section{Consumo mediático de información científica entre estudiantes de educación superior}

\author{
Scientific media consumption among higher education students
}

\author{
SILVIA DOMÍNGUEZ GUTIÉRREZ1
}

El propósito de este trabajo es mostrar a qué medios de comunicación recurren los estudiantes de educación superior cuando buscan información sobre temas científicos. A través de un cuestionario de preguntas abiertas y de opciones múltiples los 234 alumnos participantes dejan ver -con análisis de contenido mixto de por medioque prefieren en primer lugar Internet y en segundo lugar la televisión, perfilándose también la red como el medio que mayor certeza les suscita.

PALABRAS Clave: Medios de comunicación, consumo mediático, búsquedas científicas, estudiantes de educación superior.
The purpose of this paper is to pinpoint to what communication media do undergraduate students recourse when they search for scientific information. Through an open/close questionnaire the 234 students show they prefer Internet in the first place and television in second place; most of them have confidence in Internet as a source that provides scientific information.

KEY WORDS: Mass media, scientific search, media consumption, higher education students.

1 Universidad de Guadalajara, México.

Correo electrónico: silvia_dominguez_g@hotmail.com

Av. Parres Arias 150, Col. Belenes, C.P. 45100; Zapopan, Jalisco, México. 


\section{PRESENTACIÓN}

Existen en la actualidad diversas fuentes de las cuales nos valemos para obtener información acerca de algún tema en particular. Para los jóvenes, pero específicamente para aquellos que cursan una carrera universitaria, resultan indispensables ciertos medios de comunicación para estar actualizados, llevar a cabo tareas escolares y académicas, o simplemente por interés en conocer algún tema que consideren medular. En vista de la existencia de la variedad informativa, los jóvenes universitarios hacen uso de diversas fuentes para acercarse a temas relacionados con aspectos científicos. Por investigaciones anteriores (Domínguez, 2012; Domínguez \& Sánchez-Ruiz, 2009) sabemos que uno de los medios a los que ha estado expuesta una inmensa mayoría de personas es la televisión, medio accesible para todos (en los espacios urbanos hay por lo menos un televisor por familia); sabemos, también, que en algunos programas televisivos se tratan contenidos relacionados con la ciencia, los científicos y la investigación científica, aunque no en la cantidad y en los tiempos deseables.

Por otro lado, el uso de Internet entre muchos de los jóvenes ha crecido de manera apabullante; la proliferación de los cibercafés se ha incrementado (a pesar de que las computadoras en el hogar también han ido en aumento, no todas las familias en México tienen acceso a la red), y este medio se perfila como el preferido para hacer casi cualquier tipo de búsqueda. Los otros medios, como la familia, compañeros, amigos, etc., también son fuentes de información a la que acuden los estudiantes, pero en menor proporción que los medios de comunicación.

El presente estudio está dirigido a hacer un análisis de los medios que mayormente utilizan los estudiantes de pregrado (estudiantes de una licenciatura o carrera profesional) en la obtención de información relacionada con cuestiones científicas. Sabemos que la televisión es una fuente formadora de representaciones sociales de la ciencia y que está a mayor alcance que otras fuentes, pero interesa conocer otros medios utilizados y la confianza de los jóvenes en éstos. Algunas de las inquietudes para la realización de este trabajo consisten en conocer ¿cuáles son los medios más utilizados por estudiantes de licenciatura del Centro Universitario de Ciencias de la Salud (CUCS) de la Universidad de Gua- 
dalajara (UdeG) para informarse sobre temas científicos?, ¿cuáles son los preferidos y los motivos de estas preferencias?, ¿a cuáles se les tiene más confianza y por qué?

Para dar respuesta a los cuestionamientos anteriores hemos dividido este trabajo en varias secciones, siendo la primera una contextualización acerca del medio universitario que nos ocupa, seguida de un recorrido empírico por dos de los medios preferidos por los estudiantes. Las aproximaciones metodológicas las abordamos en un tercer apartado; en una cuarta sección presentamos los resultados analíticos, y en la quinta y última parte un breve corolario, para finalizar con las referencias bibliográficas.

\section{EL CONTEXTO UNIVERSITARIO}

El estudio en cuestión está inscrito en un contexto muy particular: la Universidad de Guadalajara (UdeG), que de acuerdo a Top Study Links (2012) y a Universia (2011), está ubicada como la segunda universidad más importante de la República Mexicana. ${ }^{2}$ Es la universidad pública con mayor reconocimiento estatal por su producción científica, por el número de profesores investigadores que laboran en esta institución y por los profesores que pertenecen al Sistema Nacional de Investigadores (SNI). ${ }^{3}$ Algunos datos que consolidan lo anterior, para el año 2012, son los artículos de investigación publicados en revistas reconocidas y arbitradas cuya cifra es de 1048 ; hay 509 libros publicados por profesores/investigadores; el número de citas académicas en la literatura relevante es de 554 , y $21 \%$ de los profesores han obtenido premios y distinciones por su labor docente y/o de investigación. Cabe recalcar

2 Diversas clasificaciones académicas nacionales, internacionales, públicas y privadas otorgan a la Universidad Nacional Autónoma de México (UNAM) el primer lugar entre las universidades de México y en segundo lugar a la UdeG, de acuerdo con su producción y publicación de material científico, específicamente en el servicio de información en línea provisto por el Instituto para la Información Científica (ISI, por sus siglas en inglés).

3 De los mil 585 profesores investigadores existentes en 2012, 686 eran miembros del SNI. 
que cuenta con 164 bibliotecas con un total de 2 millones 312414 volúmenes (UdeG, 2012). ${ }^{4}$

El CUCS es parte de la red universitaria de la UdeG (la que cuenta con seis centros universitarios metropolitanos y ocho regionales), lugar donde estudian los informantes que participaron en esta investigación. La población escolar total que atiende el CUCS es de 12372 alumnos, de los que 8540 son de licenciatura. El personal académico que atiende esta matrícula es de 1587 profesores de los que 214 son investigadores y de éstos 113 pertenecen al SNI. Como apoyo a las actividades académicas, este centro posee cuatro bibliotecas con 24479 títulos y 40805 volúmenes (UdeG, 2012).

El CUCS está ubicado en el tercer lugar con miembros pertenecientes al SNI dentro de la red universitaria, lo que significa que hay interés en la investigación, a la que se suman también estudiantes con estas inquietudes (como asistentes). No obstante, es notorio que son pocos los profesores investigadores de tiempo completo (214) que se dedican a estas labores, y por consiguiente son escasos los que comparten sus conocimientos en relación con la actividad científica con los alumnos de pregrado, por lo que éstos se vuelcan hacia otras fuentes en búsqueda de material de corte académico y/o científico.

Por otra parte, los estudiantes, como bien dice De Garay (2004) son uno de los núcleos importantes de la universidad, ya que son la razón de ser de cualquier organización educativa, y compartimos con este autor que el conocimiento que se tiene sobre ellos es relativamente poco. Los jóvenes alumnos universitarios son los potenciales futuros agentes creadores de políticas públicas en ciencia y tecnología, o posibles divulgadores o comunicadores de la ciencia y tecnología en sus diferentes disciplinas; es por eso que la presente investigación aborda sus consumos mediáticos, principalmente de la ciencia, y al integrar dicho análisis a estudios anteriores, poseeremos un panorama más amplio sobre sus construcciones sociales de la ciencia, sus fuentes de información e inquietudes por la actividad científica. En las siguientes secciones nos aproximamos a los jóvenes con mayor detenimiento en el tema que nos concierne.

4 Cifras reportadas hasta el 30 de septiembre de 2012. 


\section{LA TELEVISIÓN, INTERNET Y LAS BÚSQUEDAS CIENTÍFICAS}

La presencia de numerosas investigaciones acerca de los medios de comunicación, especialmente de la televisión, ha cobrado tal importancia que se han tomado muy en cuenta las diversas influencias a la exposición de este medio en ciertos grupos de telespectadores en diferentes tiempos y espacios. 5 Gerbner, Gross, Morgan y Signorielli (1994) al respecto, subrayaron:

La televisión es la fuente de imágenes y mensajes más extensamente compartida. Es el eje común simbólico del ambiente en el que nacen nuestros hijos y en el que todos vivimos nuestra vida. Su ritual de masas no da señales de flaqueza y sus consecuencias se notan cada vez más en todo el mundo. Para la mayoría de espectadores, los nuevos sistemas de entrega como cable, satélite y VCR, significan una penetración más profunda y mayor integración de las pautas dominantes, de las imágenes y de los mensajes en la vida cotidiana (p. 35).

Banchs (2007), afirma que "los medios de comunicación de masas son hacedores de representaciones en la medida en que seleccionan y difunden información y ponen de relieve temas de interés" (p. 222). Es notoria la influencia y el impacto que ejercen los medios, especialmente la televisión, en la formación de imágenes, gustos y opiniones acerca de diversas situaciones con las que nos confrontamos cotidianamente. Los medios de comunicación, pero en particular la televisión, contribuyen en la formación de representaciones sociales de diferentes aspectos, y en específico, respecto de la ciencia, existe una extensa evidencia. 6

En una reciente publicación Dudo, Brossard, Shanahan, Scheufele, Morgan y Signorielli (2011) describen que después de 25 años de la aparición de un importante reporte de investigación elaborado por Gerbner, Gross, Morgan y Signorielli en 1981 sobre la exposición a la

5 Existe un enorme listado de estudios en relación con el tema que de enunciarlos aquí nos llevaría más espacio de lo solicitado.

6 De igual manera, la lista se agranda al abordar estos temas, y por las mismas razones, se obviará el enunciarlos en este momento. 
televisión y las actitudes hacia la ciencia, llevaron a cabo un estudio con el propósito de observar dicha relación en el presente siglo XXI y ver si prevalecía la premisa original. ${ }^{7}$ Entre sus principales conclusiones se vislumbra que todavía el científico aparece con poca frecuencia en el horario de mayor audiencia, es típicamente un hombre, de raza blanca, aunque ya no asume un solo papel, sino que juega roles mixtos, es decir, no necesariamente es un científico malévolo. Con relación en los efectos de exposición acumulada a la televisión y las actitudes hacia la ciencia, permanece consistente la hipótesis del cultivo propuesta por Gerbner y colegas; no obstante, Dudo et al. concluyen que no hay una relación directa significativa respecto de las actitudes negativas hacia la ciencia en contraste con la perspectiva de hostile media (medios hostiles), sino que las imágenes del científico mostradas en la televisión son cada vez menos negativas y tienden a ser en muchos casos positivas. Dichos hallazgos son compartidos con investigaciones personales previas (Domínguez, 2012; Domínguez \& Sánchez-Ruiz, 2009).

Sin embargo, no todo radica en la televisión cuyo reinado ha imperado por mucho tiempo; cuando se trata de obtener información sobre algún tema específico relacionado con la ciencia, la selección se estrecha. Los estudios sobre el uso de Internet han ido en un aumento considerable en el presente milenio, pero al igual que con la televisión, con relación en la búsqueda de temas científicos, las investigaciones son menos numerosas. Por ejemplo, Ortiz (2012) y Kalmus, Realo y Siibak (2011) realizaron una extensa revisión bibliográfica de diferentes partes del orbe de los últimos años acerca del uso que los jóvenes hacen de la red. Ortiz (2012) concentra el material revisado en tres grupos de acuerdo a la temática y el enfoque: a) investigaciones sobre los efectos negativos que puede generar Internet en los jóvenes; b) estudios sobre el impacto de Internet en los jóvenes dentro del ámbito educativo;

7 Muchas de nuestras percepciones de la realidad son formadas o moldeadas por las imágenes provenientes de la televisión y películas a las que hemos estado expuestos. Por ejemplo, tenemos imágenes de los científicos trabajando en un laboratorio, aún cuando nunca hayamos estado presentes en un laboratorio viendo trabajar a un científico, esto es, muchas de estas imágenes puede ser que poco tengan que ver con la realidad. 
c) investigaciones sobre las apropiaciones o consumos culturales de Internet por parte de los jóvenes.

Kalmus et al. (2011) señalan que se distinguen dos perspectivas principales en el campo de las ciencias sociales en el uso de Internet: a) los estudios psicológicos que han examinado el involucramiento en varias actividades online relacionadas con características de la personalidad, y b) los estudios sobre sociología, medios, comunicación y género relacionados con los diferentes usos y preferencias de la red. Bajo estas líneas de investigación, que abarcan una buena cantidad de revisión bibliográfica, avistamos que no son predominantes los estudios sobre el uso de la red en la búsqueda de temas científicos.

En términos generales, hemos observado que las investigaciones revisadas siguen las tendencias mencionadas, pero para efectos de este trabajo nos hemos enfocado en el empleo que hacen los jóvenes estudiantes respecto de las búsquedas científicas en la red. Y a pesar de este creciente interés por los usos, impactos, consumos y consecuencias del manejo de Internet, son escasos los estudios que refieren la utilización específica de este medio para informarse sobre temas científicos, ya que la lista se acorta. ${ }^{8}$

Presentamos enseguida una somera revisión de la literatura pertinente para contrastar el uso de la televisión y de la red en la obtención de información científica. Iniciamos con estudios de corte nacional y local, para concluir con algunos de corte internacional.

En uno de los recientes reportes publicado por el Consejo Nacional de Ciencia y Tecnología (CONACYT, 2011), se presentan datos de la Encuesta sobre la Percepción Pública de la Ciencia y la Tecnología (ENPECYT) 2009 en México, realizada para valorar las opiniones de 2 mil 936 mexicanos de 18 años o más, sobre la ciencia y la tecnología, así como el consumo científico en televisión, en Internet, en radio, en periódicos y revistas. Respecto de la televisión, el reporte señala que 96.4\% de las personas entrevistadas ven televisión (en promedio tres

$8 \quad$ En el portal Research on Social Network Sites (s.f.) se presenta un enorme listado donde se enumeran 472 títulos de investigaciones acerca de la red en sus múltiples campos y usos, aunque de este extenso listado, apenas unas cuantas hacen referencia a la obtención de información científica. 
horas al día), y de ese porcentaje $42.5 \%$ ve programas de ciencia y tecnología; es decir, poco más de un tercio observa programas con algún contenido científico o tecnológico. Con relación al uso de Internet, $60.9 \%$ accedía a la red con cierta frecuencia; $56.9 \%$ lo hacía en promedio una hora diaria; $17.4 \%$ entre una y dos horas diarias, y $25.7 \%$ se conectaba a la red por más de dos horas diarias. De ellos, 83.8\% consultaba su correo electrónico, siendo este el principal uso. El consumo científico en la red era bajo: las búsquedas de temas relacionados con la tecnología se ubicaban en el sexto lugar, y en el onceavo (de 15 lugares) la ciencia, es decir, en los últimos lugares.

Márquez y Tirado (2009) realizaron una investigación con 1808 estudiantes entre 14 a 18 años de edad de la ciudad de México de diferentes escuelas, a los que se les pidió dar su opinión sobre varios medios. Del total, $85.8 \%$ considera que Internet "es una herramienta indispensable en la época actual" y $85.2 \%$ cree que es "una verdadera revolución para la vida cotidiana". Se exploró también su aprendizaje sobre ciencia en los diversos espacios o medios en los que los adolescentes reportaron que han aprendido más sobre ciencias en la escuela (97.7\%), en los museos interactivos de ciencia y tecnología (96.2\%), en los libros (92.8\%), en Internet (87.3\%), en revistas y periódicos $(85.6 \%)$ y en la televisión (83.4\%). Apuntan los autores que llama la atención que Internet se encuentra ligeramente mejor posicionado que la televisión como medio de aprendizaje, aunque paradójicamente más adelante señalan que los estudiantes recuerdan haber visto más temas de ciencia en la televisión que en Internet.

Existen varios estudios realizados por De Garay (2001, 2004, 2006, 2009 , entre otros) en los que refiere a los jóvenes universitarios y sus diversas prácticas cotidianas. Retomamos aquellos en que se detalla el consumo de los medios de comunicación en particular, elementos esenciales de nuestra investigación. En 2001, De Garay publicó un estudio que llevó a cabo en varias universidades y tecnológicos de ciudades como Tijuana, Monterrey, Colima, Pachuca, Veracruz, Distrito Federal, Oaxaca y Mérida, con una participación de 9 mil 811 estudiantes. Respecto de las estrategias para la obtención de materiales de estudio, señala que el uso de los servicios de la biblioteca y sacar fotocopias fueron las prácticas más ampliamente generalizadas por los alumnos (86.7\%). 
En menor proporción, pedir prestados los textos, comprar libros y entrar a Internet fueron prácticas realizadas por 4 de cada 10 estudiantes. No obstante, explica el autor que fue impresionante observar el aumento del uso de Internet, puesto que $40.7 \%$ dijo hacerlo "siempre" o "casi siempre" a pesar de que $80 \%$ no podía acceder a la red desde su casa.

En 2009 el mismo autor reportaba un seguimiento a una generación de estudiantes de la Unidad Azcapotzalco de la Universidad Autónoma Metropolitana (UAM) de la ciudad de México, seguimiento que inició en 2003 con 1203 alumnos y concluyó en mayo de 2007 con 54.3\% de los inscritos. Bajo el mismo rubro de la investigación precedente, las estrategias para la obtención de materiales de estudio no tuvieron variaciones cuando los estudiantes iniciaron sus estudios y un año después, ya que el hacer uso de la biblioteca de la Unidad (88.8\%), sacar fotocopias $(80.3 \%)$ y obtener información de Internet $(72.3 \%)$ fueron las prácticas más socorridas. Sin embargo, cuando los estudiantes cursaban el cuarto año, aumentó considerablemente la proporción de quienes usaban Internet (tanto en el centro de cómputo de la Unidad, de los cibercafé y en casa), en tanto que bajó el uso de las fotocopias. Con relación en el consumo televisivo, acota De Garay que $69.9 \%$ de los estudiantes en su primer año en la UAM Azcapotzalco dedicaban más horas a ver televisión (entre 1 y 5 horas por semana) que a estudiar fuera del aula, asunto que se revierte con el paso por la universidad, ya que en su cuarto año los alumnos dedicaban más tiempo a leer que a ver televisión.

En el ámbito local y particular que nos atañe, Haro, Cabrera, Tornero, González y Carrillo (2011) realizaron una investigación para abordar el consumo cultural, el tiempo libre y los medios electrónicos en 610 estudiantes del CUCS de UdeG, alumnos de primer ingreso de cinco carreras de licenciatura. Aunque el estudio no da cuenta de detalles finos ${ }^{9}$-se encuentra en una fase exploratoria-, proporciona al-

9 Por ejemplo, a qué tipo de consumo cultural se refieren, a qué dedican su tiempo libre los estudiantes por una parte, y por otra solo hacen mención a un medio electrónico -Internet- $\mathrm{y}$ de éste no señalan qué redes, espacios o páginas visitan los alumnos. No obstante, es una investigación que nos concierne directamente por haberse realizado con estudiantes del mismo centro universitario al igual que la autora de este trabajo. 
gunos datos relevantes; por ejemplo, se deriva que $67.54 \%$ utiliza de manera frecuente Internet y $17.3 \%$ lo utiliza siempre; solo $15.1 \%$ lo hace de vez en cuando. Sin embargo, de manera global, se desprende que el consumo cultural, del tiempo libre y de Internet que hacen los jóvenes encuestados del CUCS, se encuentra ubicado en los niveles medio y bajo.

Finalmente, en el ámbito iberoamericano, Vogt, Morales, Righetti y Caldas (2011) refieren la articulación jóvenes/ciencia en diferentes dimensiones, entre ellas, los hábitos informativos sobre ciencia y tecnología en 9 mil estudiantes de nivel medio de ocho ciudades (Asunción, Bogotá, Buenos Aires, Lima, Madrid, Montevideo, Santiago y São Paulo); estudio realizado entre 2008 y 2010. Confirman los autores que es poco el consumo de los jóvenes en temas de ciencia y tecnología, ya que sus respuestas coincidían con las opciones "nunca" o "casi nunca". Más cuando se tenía que acudir a ciertos medios para obtener dicha información, la televisión fue priorizada por los jóvenes encuestados (con excepción de los bonaerenses y madrileños que señalaron no ver televisión). El segundo medio al que acudieron los jóvenes para este tipo de búsquedas era Internet, siendo mas popular entre los chicos de Asunción y Bogotá. Observamos que tanto la televisión como la red son los medios favorecidos por los jóvenes iberoamericanos encuestados para indagar sobre temas de ciencia y tecnología.

Los estudios precedentes revelan el uso de la televisión e Internet respecto de búsquedas científicas en el ámbito nacional, local e iberoamericano. Veamos algunos estudios provenientes de Estados Unidos para completar el panorama. ${ }^{10}$ Horrigan (2006) expone que cuando se les preguntó a 2 mil personas (mayores o igual a 18 años) acerca de cuál era la fuente principal utilizada para informarse en temas científicos, $41 \%$ citó a la televisión, $20 \%$ a Internet, $14 \%$ a las revistas, $14 \%$ a los

10 Incluimos solo este país anglosajón por su cercanía con los países latinos, especialmente con México, y por el impacto que revierte esta gran potencia en los países en desarrollo en cuestión de ciencia y tecnología. No menospreciamos las investigaciones provenientes de otras partes del orbe, pero dar cuenta de ellas en este trabajo no es parte de los propósitos por el momento. 
periódicos, 4\% a la radio, y el resto porcentual mencionó otras fuentes. La visión cambia cuando el análisis se centra en la población menor a 30 años de edad, ya que $36 \%$ de jóvenes señaló que obtiene más información científica e información de tipo general de la televisión, seguido de 34\% que citó a Internet; estas dos últimas cifras revelan que básicamente no hay diferencia, es decir, la televisión pierde popularidad entre este grupo etario; incluso, Internet es la primera fuente a la que se recurre cuando se necesita información sobre un tema específico, y las bibliotecas son la segunda opción en lugar de la televisión. Eso acontecía en 2006.

Ibope Zogby International llevó a cabo una encuesta en 2009 a 3 mil 030 estadounidenses residentes en diversas ciudades de dicho país para conocer a través de qué medios se informaban (UTICA, 2009). En el breve reporte se da cuenta de que 56\% manifestó que si tuviera que escoger una sola fuente de información, elegiría Internet, mientras que $21 \%$ preferiría la televisión; los periódicos y la radio serían la opción de $10 \%$ de los encuestados. La red también fue preferida por $40 \%$ como la fuente de noticias más confiable, mientras que apenas $17 \%$ dijo confiar en la televisión, $16 \%$ en los periódicos, $13 \%$ en la radio y $14 \%$ restante mencionó no estar seguro. Los resultados del estudio posicionan a Internet en una situación privilegiada en cuanto a la búsqueda de información y refleja un aumento considerable en su credibilidad.

El informe de la National Science Foundation (2012) corrobora que el ambiente de los medios ha estado cambiando en la última década. No obstante, una pluralidad de estadounidenses coinciden todavía en que la televisión es su fuente principal, en la captación de noticias, pocos mencionaron que esta fuente sea confiable en la obtención de información científica y tecnológica, siendo para una gran mayoría Internet su fuente principal como se observa en la Figura 1.

Es notorio el uso y confianza en Internet en la búsqueda de información científica; el reporte concluye que es mayor entre los jóvenes y se incrementa de acuerdo con el nivel educativo y con el ingreso económico, a diferencia de los adultos que buscan y confían más en la televisión, aunque también esté decreciendo entre este grupo etario. 


\section{FIGURA 1}

FUENTES PRIMARIAS EN LA OBTENCIÓN DE INFORMACIÓN CIENTÍFICA (PORCENTAJES)

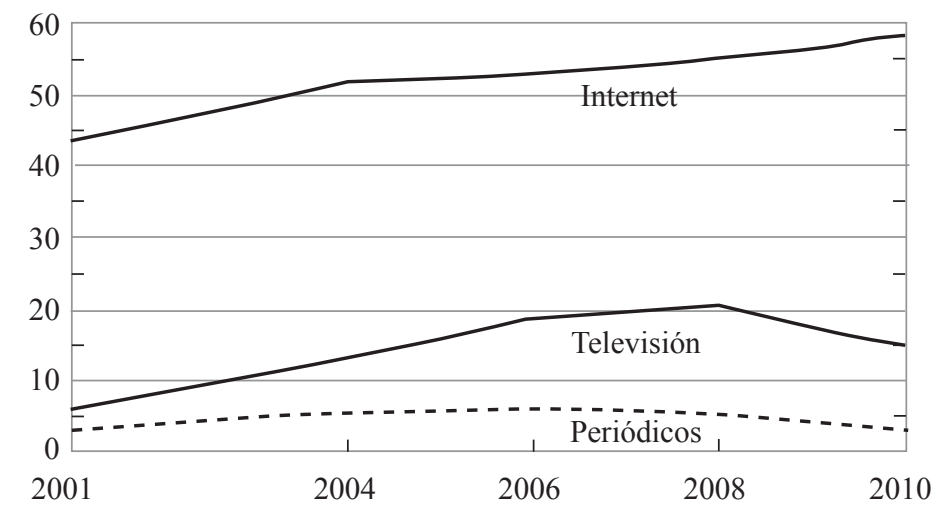

Fuente: National Science Foundation.

\section{ACERCAMIENTOS METODOLÓGICOS}

\section{Participantes}

La presente es parte de una investigación en el largo plazo que inició en 2006 y en la que han habido diversos cortes temporales de análisis, cuyo objetivo general es analizar a los estudiantes de todos los centros pertenecientes a la red de la UdeG respecto de sus representaciones sociales de la ciencia. En esta ocasión (ciclo escolar 2009-2010) colaboraron 234 estudiantes de seis licenciaturas (Cultura Física y Deportes, Enfermería, Nutrición, Medicina, Odontología y Psicología) del CUCS. Los grupos de alumnos fueron seleccionados al azar (tomando como parámetro el horario de clases de 9 a 11 a.m.), correspondiendo a 120 alumnos de primer semestre (20 por carrera) y 114 de los últimos semestres (19 por carrera). Son jóvenes de entre 18 y 22 años de edad, estudiantes regulares de educación superior, de clase media (baja y alta); la mayoría se dedica únicamente a sus estudios profesionales y una cuarta parte divide su tiempo entre trabajar y estudiar. No distinguimos, por el momento, los resultados por carrera de adscripción ni por grado. 


\section{Herramienta en la producción de información}

Utilizamos un cuestionario compuesto de 27 preguntas con opciones múltiples y preguntas abiertas, algunas de estas son: “¿qué tan informada(o) te consideras en temas relacionados con la ciencia?", "cuando te informas sobre cuestiones científicas, ¿por qué lo haces?", "de los siguientes medios, señala cinco (de mayor a menor ) a los cuales recurres con mayor frecuencia para obtener información científica", "si utilizas Internet, ¿por cuánto tiempo te conectas a diario?”, “¿qué es lo que más haces cuando estás en Internet?", entre otras; preguntas de las que retomamos solo las más relevantes para el presente trabajo.

\section{Análisis}

La información proporcionada por los alumnos fue codificada y trasladada a hojas Excel para la cuantificación de las frecuencias (tanto para preguntas cerradas como abiertas). Una vez efectuado lo anterior, se procedió a hacer tablas dinámicas que fueron utilizadas en la elaboración de las tablas finales y los gráficos correspondientes con la intención de analizar, mediante estrategias de triangulación, las preferencias y los medios en quienes más confían los informantes cuando se trata de buscar temas científicos.

\section{RESULTADOS ANALÍTICOS}

Iniciamos con las respuestas a la pregunta acerca de a cuáles medios acudían los estudiantes para obtener información científica, las que se aprecian en la Tabla 1. Se les solicitó a los estudiantes que marcaran cinco medios o fuentes a los cuales recurrían con mayor frecuencia. ${ }^{11}$

11 La primer opción corresponde al medio o fuente a la que primero recurrían para obtener información científica y la quinta opción se refiere a la última a la que acudían. Las opciones presentadas en la pregunta son las mismas que se exhiben en la Tabla 1. 


\section{TABLA 1}

MEDIOS PREFERIDOS PARA INFORMARSE SOBRE CIENCIA (PORCENTAJES)

\begin{tabular}{|c|c|c|c|c|c|c|c|c|c|c|}
\hline & 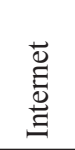 & 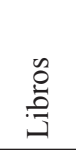 & $\gtrless$ & 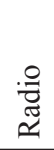 & $\frac{\sqrt[\pi]{\pi}}{\sqrt[0]{0}}$ & 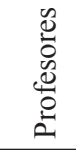 & 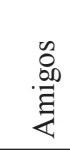 & 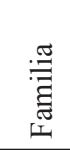 & 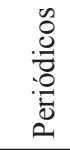 & $\stackrel{\circ}{0}$ \\
\hline \multicolumn{11}{|l|}{ Primer } \\
\hline Opción & 45.0 & 26.8 & 17.8 & 3.6 & 3.6 & 1.6 & 1.6 & & & \\
\hline \multicolumn{11}{|c|}{ Segunda } \\
\hline Opción & 31.0 & 19.6 & 16.1 & 1.8 & 8.6 & 16.1 & & 3.4 & 3.4 & \\
\hline \multicolumn{11}{|l|}{ Tercera } \\
\hline Opción & 13.0 & 13.0 & 8.6 & 5.1 & 16.1 & 26.8 & 5.1 & 1.8 & 10.5 & \\
\hline \multicolumn{11}{|l|}{ Cuarta } \\
\hline Opción & 7.4 & 14.3 & 7.0 & 3.6 & 21.4 & 21.4 & 12.5 & 1.8 & 8.8 & 1.8 \\
\hline \multicolumn{11}{|l|}{ Quinta } \\
\hline Opción & 3.6 & 5.4 & 16.1 & 3.6 & 21.4 & 10.7 & 7.0 & 12.5 & 16.1 & 3.6 \\
\hline
\end{tabular}

Fuente: Elaboración propia.

Se aprecian en este concentrado los diferentes medios a los que acuden los jóvenes cuando desean consultar algún tema científico en particular. Es importante señalar, antes de entrar de lleno en el análisis, que nuestros participantes tienen la característica principal de ser estudiantes de educación superior; por lo tanto, esta muestra es diferente de aquellas que forman las encuestas -a partir de otro tipo de poblaciónque se mencionan en los estudios o reportes que presentamos anteriormente. Esto significa, entre otros aspectos, que nuestros informantes tienen muy presente el ámbito académico, 12 y por lo mismo los libros, los maestros o profesores, los amigos y compañeros están muy arraigados en el ambiente universitario, de allí las búsquedas primarias en estos medios; no obstante si observamos detenidamente, son los medios de comunicación los que predominan. Entonces, para efectos del tema

12 Incluso el cuestionario fue aplicado en su salón de clases, en el ambiente académico/estudiantil en el que ellos se desenvuelven cotidianamente. 
que nos concierne, solo haremos mención de los medios de comunicación favoritos en la indagación de temas científicos.

Así, observamos en la Figura 2 que como primera opción de búsqueda, los medios de comunicación ${ }^{13}$ a los que más acuden los estudiantes participantes son Internet, la televisión, la radio y las revistas, para obtener información de tipo científica. Vemos la consolidación de Internet como el medio favorito (45\%), ya que casi la mitad de los estudiantes lo prefieren para hacer búsquedas científicas.

FIGURA 2

PRIMERA OPCIÓN PARA INFORMARSE SOBRE TEMAS CIENTÍFICOS

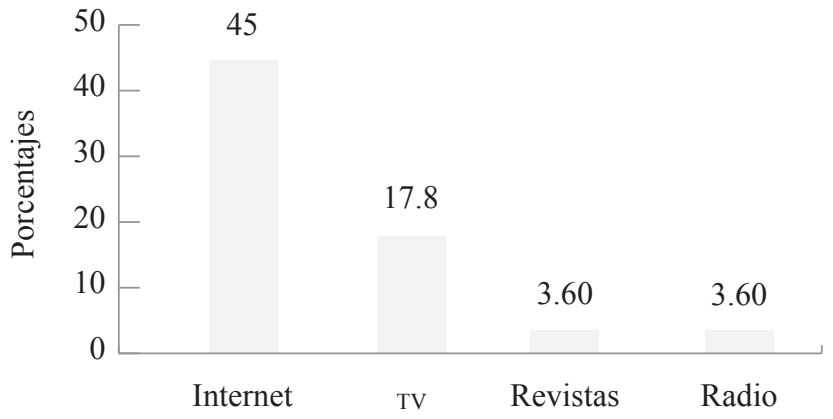

Fuente: Elaboración propia.

Un gran número de alumnos señaló a Internet, ya que para éstos es una opción rápida, no costosa y de fácil acceso para hacer búsquedas de cualquier índole. Como uno de ellos apuntó: "La tienes a la mano y es más fácil encontrar lo que andas buscando, ya sea para tareas o

13 Manuel Castells (2009) dice que "Internet, la World Wide Web y las comunicaciones inalámbricas no son medios de comunicación en el sentido tradicional. Más bien son medios de comunicación interactiva. Sin embargo, al igual que la mayoría de analistas de este campo, sostengo que las fronteras entre medios de comunicación de masas y demás formas de comunicación son difusas" (p. 99). Aunque compartimos la opinión de Castells, no aludimos a las diferencias enunciadas por él, sino que tomamos a estos medios de comunicación de manera similar para los propósitos de este artículo. 
por simple curiosidad". Una alumna señala: "Todos los chavos estamos muy acostumbrados a usar Internet para todo, por lo menos yo sí, pero además uno encuentra lo que busca porque allí está todo o casi todo, para mí es súper indispensable". Otro agrega: "En la casa muchas veces no tienes los libros con la información que quieres o te piden, y pues en Internet ahorras mucho tiempo y dinero porque hay unos libros muy caros". Por otra parte, 95\% señaló tener acceso a la red en el hogar, por lo que para este grupo en particular de alumnos acceder a la red no constituye ningún problema. ${ }^{14}$ Del total, $58.12 \%$ pasa entre tres y cuatro horas diarias conectados a Internet, lo que significa que más de la mitad de los jóvenes estudiantes pasan una buena cantidad de tiempo en la red. De ese tiempo, el mayor periodo lo dedican a hacer búsquedas para la elaboración de tareas, estar en alguna red social (Facebook fue la más citada), chatear y revisar su correo electrónico, en ese orden. Las páginas web o portales más recordadas y visitadas por los alumnos para la realización de las tareas o consultas científicas en general son Google, la biblioteca virtual de la UdeG, Wikipedia, Monografías y Scielo. Inferimos, por lo tanto, que la mayoría de los alumnos no hacen búsquedas adecuadas para obtener información científica en las páginas especializadas para ello, con excepción de dos estudiantes que mencionaron el portal de Scielo (Scientific Electronic Library Online, página que reúne una colección de revistas y artículos científicos).

Es importante recalcar que nuestros informantes pertenecen a un grupo estudiantil con necesidades particulares en el consumo de medios, por lo que es fácil entender que la red sea la principal fuente de consulta para las búsquedas científicas. En este sentido, se confirman las tendencias tanto nacionales como internacionales ${ }^{15}$ respecto del uso de este medio por los jóvenes para este tipo de consultas. Más aún, el

14 Cabe resaltar una vez más que los estudiantes informantes que participaron en esta investigación constituyen una muestra un tanto particular o diferente de aquellas reportadas en los estudios precedentes, representativas de otras poblaciones, razón por lo que muchos de nuestros datos no coinciden, principalmente, con las encuestas nacionales precisamente por estas peculiaridades.

15 Véase también The Pew Research Center for the People and the Press (2011). 
informe de la Asociación Mexicana de Internet (AMIPCI, 2012) ratifica datos y las tendencias generales: durante 2012 el tiempo diario de conexión a la red por parte del internauta mexicano fue de 4 horas y 9 minutos, siendo las principales actividades online el enviar/recibir mails $(80 \%)$, acceder a redes sociales $(77 \%$, Facebook la más usada) y hacer búsquedas de información (71\%). Jalisco (estado en que radican nuestros informantes) está ubicado como la tercera entidad federativa con mayor número de cibernautas, 3 de cada 10 hogares cuentan con computadora, de las que $76 \%$ poseen conexión a Internet. 16

Respecto de la televisión, no es de extrañar que siga siendo una fuente de consulta importante, puesto que para casi una sexta parte (17.8\%) lo es, no obstante haya una buena distancia con la red (más de 20 puntos porcentuales). La televisión ha sido reconocida como formadora de representaciones sociales de la ciencia en niños desde muy temprana edad; ciertas caricaturas y algunas películas muestran figuras estereotipadas del científico y esas imágenes son perpetuadas hasta la edad adulta. Sabemos que hay televisores en casa, trabajo, escuela, lugares de entretenimiento, etc., por lo que está casi en todos lados. Aún así, la diferencia radica en los programas que se vean. De hecho, aproximadamente $35 \%$ de hogares mexicanos tienen algún tipo de televisión de paga (Cablevisión, Megacable, Telecable, Sky, Dish) que ofrecen mayor número de canales en donde se pueden apreciar programas de divulgación científica (los de tipo Discovery, que podríamos considerar como canales temáticos), a diferencia de los canales abiertos en los cuales las opciones son más restringidas y de menor calidad en la programación, no obstante haya excepciones (Canal 11 y 22, en el nivel nacional, y 44 y C7 en el local -Jalisco-). Estos jóvenes estudiantes en particular, señalaron que ven muy poca televisión, pues el trabajo o las tareas no les permiten estar atentos a programas que les gustaría ver, por lo que la gran mayoría $(83 \%)$ dijo verla ocasionalmente. Es expli-

16 De acuerdo a la AMIPCI (2012), se reporta la conexión a Internet en 76\% de los hogares jaliscienses; no obstante, hay que hacer notar que $95 \%$ de los estudiantes participantes en el presente estudio mencionaron tener acceso a la red en casa, lo que posiblemente se deba a presiones de los jóvenes hacia los padres para poder conectarse a Internet y hacer tareas. 
cable que señalen lo anterior, ya que gran parte de su tiempo libre están conectados a Internet, aunque bien pudieran ver televisión a través de éste, cosa que no se reportó aún.

Le siguen en opciones la radio y las revistas, ambas empatadas en el tercer lugar, aunque con buena diferencia con la televisión, y no se diga con Internet. Lo anterior representa que la mayoría de los estudiantes prefiere informarse sobre temas científicos a través de Internet y la televisión, y muy pocos lo hacen a través de la radio y las revistas. De ellos $67 \%$ dijo escuchar la radio, pero de esta gran mayoría que escucha la radio, pocos oyen noticieros (aunque esto no necesariamente implique que escuchen dentro de las noticias algo que se refiera a la ciencia o la tecnología en términos generales) o programas especiales con algún contenido científico, es decir, apenas 3.6\% dice hacerlo. Lo mismo sucede con las revistas que detallamos más adelante. Este esquema casi se repite para la segunda opción que se pormenoriza en la Figura 3.

FIGURA 3

SEGUNDA OPCIÓN PARA INFORMARSE SOBRE TEMAS CIENTÍFICOS

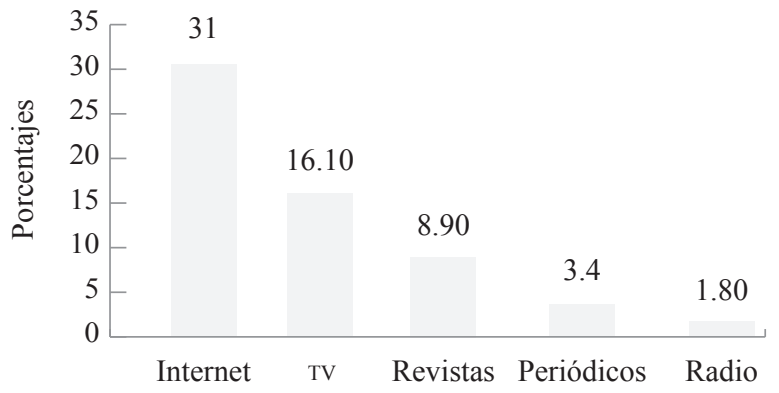

Fuente: Elaboración propia.

Se observa que siguen como punteros la red y la televisión como medios principales en la obtención de información científica, pero enfoquémonos en las revistas. El papel de las revistas es mayor como segunda opción (no obstante lejana a la red y la televisión), ya que 8.9\% las prefiere por sobre los periódicos y la radio, aspecto revelador, ya que 55.98\% dijo que sí leían revistas científicas en una de las preguntas. No obstante, 
para muchos de estos alumnos (38\%), las revistas que ellos catalogan como científicas son principalmente de divulgación científica como Muy interesante, Quo, National Geographic, y solo apenas $0.1 \%$ citó revistas propiamente científicas como el Journal of American Clinical Nutrition, Nature y la Revista de Salud Pública de México; el resto no se acordó de los nombres de las revistas, no contestó o citó otras como Reader's Digest, Proceso, etc. Es notoria la escasa formación e información de los alumnos en la distinción entre las revistas científicas de aquellas que solo divulgan parte de las investigaciones científicas.

Por otra parte, nuestros hallazgos coinciden con la Encuesta Nacional de Lectura (2006) que reporta que 39.9\% de las personas de diferentes estados de México, Jalisco incluido, dijo leer revistas pero en las que predominan las de tipo espectáculos (39.9\%), femeninas $(34.6 \%)$, de música (21.1\%), de información televisiva (21\%), deportes $(19.6 \%)$, de cultura/ arte/literatura (16.1\%), y solo $11.4 \%$ dijo leer revistas científicas.

Destacamos la inclusión de los periódicos como segunda opción aunque no muchos de los estudiantes prefieran este medio, ya que del total apenas 3.4\% señaló hacer búsquedas en la prensa escrita. Cabe señalar que muy pocos leen los periódicos, puesto que al preguntárseles con qué frecuencia los leían, 5.98\% dijo leer el periódico todos los días, $18.08 \%$ lo hace de dos a tres veces por semana, $24.05 \%$ una vez por semana, $25.50 \%$ menos de una vez por semana y $26.39 \%$ nunca lee el periódico. De los 234 estudiantes informantes, solo 3 dijeron leer el periódico en Internet, lo que también confirma la poca o nula referencia de este medio (prensa) dentro de otro (Internet). El hallazgo difiere de lo encontrado en las investigaciones citadas anteriormente (Horrigan, 2006; National Science Foundation, 2012; UTICA, 2009), ya que de acuerdo a dichos estudios parece que la población anglosajona encuestada lee el periódico con mayor frecuencia que nuestros estudiantes. Incluso entre los datos reportados por la Encuesta Nacional de Lectura (2006), en la que se entrevistaron a 4057 personas, 42\% indicó leer el periódico, lo que contrasta con datos reportados por Sánchez-Ruiz (1994) en que en esa época 52.7\% dijo leer periódicos. Al parecer, nuestros estudiantes informantes se alejan considerablemente de las cifras referidas, pero de nuevo, nuestra muestra no pretende ser representativa 
de la población adulta nacional, aspecto que deberá ser considerado con mayor atención.

Como tercera opción, los alumnos acuden más a las revistas, como apreciamos en la Figura 4, aunque la tendencia sigue más o menos el mismo rumbo, es decir, le siguen por orden descendente Internet, los periódicos, la televisión y la radio.

FIGURA 4

TERCERA OPCIÓN PARA INFORMARSE SOBRE TEMAS CIENTÍFICOS

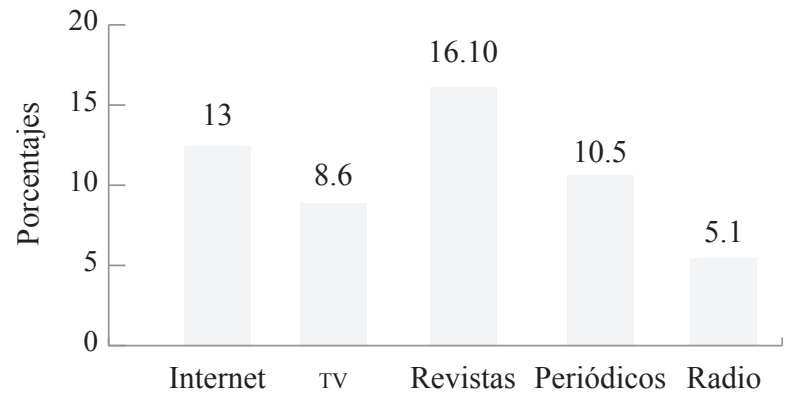

Fuente: Elaboración propia.

No obstante que las revistas sean las punteras como tercera opción, observamos que Internet se encuentra dentro de los primeros lugares en cualquiera de las tres opciones, lo que es diferente para la televisión que se ubica en el cuarto lugar en esta opción en particular, aunque percibimos que las distancias entre cada uno de estos medios son más o menos simétricas, con excepción de la radio.

Respecto de este último medio de comunicación, notamos que está presente en las tres opciones, aunque sea en el último lugar pero aún así es considerado por los alumnos. De éstos, $66.24 \%$ dijo escuchar la radio, lo cual es significativo porque más de la mitad todavía utiliza este medio y como ellos mismos comentaron "aunque solo para escuchar música". Por otra parte, $32.05 \%$ señaló que no escucha radio y $1.71 \%$ de los estudiantes no contestó. De ese $66.24 \%$ que dijo oír la radio, $78.21 \%$ no escucha ningún programa en que se aluda a la ciencia; esto implica que más de tres cuartas partes de los radioescuchas informantes no atienden a 
ningún programa con contenido científico. De los pocos que contestaron que sí escuchan información científica (11.53\%), casi ninguno recuerda el nombre del programa o la estación ("mi mamá lo escucha, pero no recuerdo cómo se llama el programa", "algo así como el tlacoache”, "no sé la estación", "no me acuerdo"), incluso, nombraron programas/ estaciones en los que se dan consejos para solucionar algún problema de salud o aspecto psicológico -relaciones familiares, sexuales, sentimentales-, etc., o se trata alguna problemática nacional o local, por ejemplo "Qué tal Fernanda", "Radio Metrópoli", "Radio Gallito", "Adela Micha" o "Hechos, de radio UdeG". Solo uno mencionó el programa "Domingo en la ciencia" y la frecuencia de transmisión (93.9).

Otra cuestión no menos importante es la confianza que se les tiene a estos medios de comunicación en la obtención de información científica. Lo apreciamos con mayor claridad en la siguiente figura.

\section{FIGURA 5}

¿A QUIÉN LE TIENES MAYOR CONFIANZA PARA RECIBIR INFORMACIÓN SOBRE TEMAS CIENTÍFICOS?

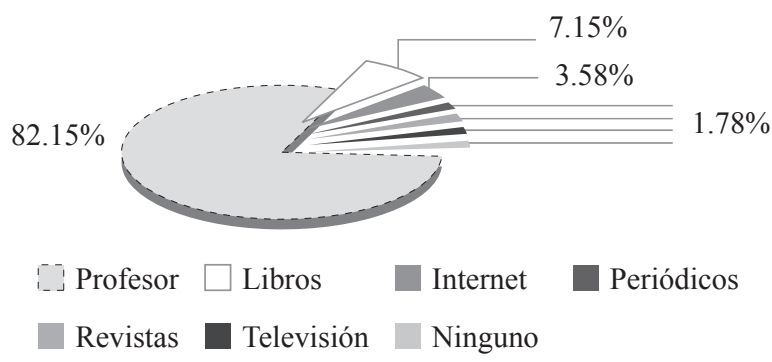

Fuente: Elaboración propia.

Presentamos todas las respuestas para dar cuenta de manera global a quiénes o a qué se le tiene mayor confianza para informarse sobre aspectos científicos. Es notoria la confianza depositada en los profesores y en los libros, que como decíamos anteriormente, resulta un tanto na- 
tural dicha respuesta ya que nuestros informantes están muy compenetrados del ambiente académico, además de que el profesor universitario representa autoridad y profesionalismo en la mayoría de los casos. ${ }^{17}$ No nos detendremos en dichas respuestas porque no es el propósito del estudio, pero sí era importante presentar el panorama general para deducir con mayor asertividad el resto de las réplicas.

Entonces, apreciamos que los alumnos apenas confían en los medios de comunicación cuando de ciencia se trata, notándose que Internet a pesar de ser un medio muy utilizado, no es el que mayor certeza les provoca (solo para $3.58 \%$ de los estudiantes), aunque de los medios de comunicación (televisión, periódicos y revistas, con $1.78 \%$ cada uno) es al que le tienen más confianza. Si sumamos los porcentajes obtenidos en los medios de comunicación, tenemos que un total de $8.92 \%$ de los alumnos confían en éstos para la obtención de información científica, versus $89.3 \%$ de estudiantes (suma de porcentaje de confianza a profesores más el correspondiente a libros), quienes confían más en los medios formales (educativos) para obtener datos científicos. Es decir, predomina la confianza en el ámbito institucional/escolar.

Por otra parte, es importante destacar la poca o nula confianza que le tienen los estudiantes a las revistas científicas, que aunque no son las más buscadas, sí son de las primeras opciones de consulta y están al alcance en las bibliotecas de las universidades. Tenemos conocimiento que solo una mínima parte conoce las características de una revista científica y quizá por ello la desconfianza hacia las que ellos creen que son científicas. En este caso, la desconfianza se debe más al desconocimiento de cuáles son las revistas de corte científico, que a la certeza que les puedan provocar éstas.

Algo parecido sucede con la televisión. A pesar de que varios de los estudiantes prefieren los programas de los canales temáticos (los de tipo Discovery o National Geographic que ofrecen más bien documentales en diferentes áreas), los muchachos los ven pero como programas alternativos, no tanto para hacer búsquedas científicas, más en este nivel de educación superior. Sostenemos que la poca confianza

17 Aún así, hay construcciones sociales ambivalentes hacia la figura del profesor. En Domínguez (2012) se pormenorizan dichas percepciones. 
que la televisión les merece a los estudiantes es referida a los noticieros principalmente. 18

Para finalizar, comentaremos una encuesta de Consulta Mitofsky (2011) que da a conocer el perfil del usuario mexicano de redes sociales en Internet; en ésta se describe que los cibernautas (principalmente jóvenes de entre 18 a 29 años de edad) seguidores de Facebook a quien más confianza le tienen - de una lista de 15 opciones-son a las universidades $(12.9 \%)$, en quinto lugar se encuentran los medios de comunicación (5.7\%) y en último lugar los diputados $(1.1 \%)$. Aunque el reporte ofrece información en general, destaca la similitud con nuestros informantes sobre la confianza en las universidades (de las que el profesor forma parte), y relativamente cercanos a la confianza en los medios de comunicación. Por otra parte, con relación en Internet, cabe señalar que tanto nuestros informantes como los ciudadanos estadounidenses encuestados, confían más en Internet para este tipo de búsquedas específicas, que en la televisión. Pareciera que las comparaciones entre estos dos medios fueran de rivalidad, mas en realidad no lo son. Como apunta Castells (2009):

Carece de sentido comparar Internet con la televisión en términos de "audiencia" como sucede a menudo con los análisis trasnochados de los medios de comunicación. De hecho, en la economía de la información, la mayor parte del tiempo que se consume en Internet es tiempo de estudio o de trabajo. No "vemos" Internet como vemos la televisión. En la práctica, los usuarios de Internet (la mayoría de la población en las sociedades avanzadas y una proporción cada vez mayor del Tercer Mundo) viven con Internet. Como se ha podido constatar en múltiples investigaciones, Internet, en sus distintas aplicaciones, es el tejido de la comunicación de nuestras vidas: para el trabajo, los contactos personales, la información, el entretenimiento, los servicios

18 Recordemos las marchas de protestas de jóvenes estudiantes de diferentes universidades que sucedieron en el mes de mayo de 2012, respecto de la propaganda electoral en pro del candidato del PRI a la presidencia de México emitida en uno de los noticieros de mayor rating, Televisa. Entre sus reclamos sobresalieron la manipulación mediática en pro de este candidato y la poca credibilidad de los jóvenes hacia este noticiero cuyos fines evidentemente eran electorales. 
públicos, la política y la religión. ... Además, Internet se usa cada vez más para acceder a medios de comunicación (televisión, radio, periódicos), así como a cualquier forma de producto informativo o cultural digitalizado (películas, música, revistas, libros, artículos de periódicos, bases de datos). La red ya ha transformado la televisión. Los adolescentes entrevistados por investigadores del USC Center for the Digital Future ni siquiera comprenden la idea de ver la televisión con un horario ya programado. Ven programas enteros de televisión en la pantalla del ordenador y, cada vez más, en dispositivos portátiles. Así pues, la televisión sigue siendo un medio de comunicación de masas importante, pero su formato y recepción están cambiando a medida que la recepción se personaliza (p. 100).

Si bien Castells destaca la función de estos dos medios con sus peculiaridades en un ámbito de explicación general, nosotros particularizamos con las búsquedas de tipo científicas, en la que Internet lleva la delantera.

\section{COROLARIO}

Los medios de comunicación favoritos para consultas científicas en nuestros informantes son Internet y la televisión, pero con una predilección hacia el primero. Destaca que nuestros hallazgos tienen semejanzas con los estudios realizados en otras partes del orbe, incluyendo las investigaciones en el nivel nacional reportadas en este trabajo, de lo cual podemos colegir que se guardan similitudes globales, quizás impuestas por las políticas económicas empoderadas con una tecnología (Internet, por ejemplo) de fondo muy productiva -para algunos- que hace que converjamos en tendencias simultáneas, no obstante desiguales (Castells, 2009; Sánchez-Ruiz, 2005). De igual manera, también coincidimos en que la búsqueda de información científica en estos medios de comunicación es poca (a menos que se tenga que hacer para cumplir una tarea, pero casi de manera obligada), puesto que los estudiantes $-\mathrm{y}$ la ciudadanía en general- están concentrados en quehaceres diferentes de la actividad científica, ya sea porque la conciben lejana e inaccesible, porque no les interesa o por otro buen número de razones. Por otra parte, nuestros informantes desconocen la práctica de investigar textos 
científicos en Internet, ignoran cuáles son las características de los artículos científicos y tampoco ubican los sitios dónde localizarlos. No obstante el uso cotidiano y en constante aumento de la red puede acrecentar cierto interés hacia estas cuestiones (aunque sea por casualidad), ya que el fácil acceso y la comodidad que brinda hacerlo desde el hogar, trabajo o escuela, contribuyen a estar más alertas a los acontecimientos, tengan una relación directa o no con la ciencia; si a esto le agregamos las asesorías continuas y pertinentes por parte de los docentes, investigadores y expertos en temas de ciencia y cómo localizar las fuentes de manera más asertiva en cualquier medio, se culminaría -en el largo plazo- con una población estudiantil "alfabéticamente científica", 19 en el mejor de los casos.

\section{Bibliografía}

Asociación Mexicana de Internet-AMIPCI. (2012). Hábitos de los usuarios de Internet en México. Recuperado el 18 de agosto de 2012 de http://www.amipci.org.mx

Banchs, M. A. (2007). Entre la ciencia y el sentido común: representaciones sociales y salud. En T. Rodríguez \& M. García (Coords.), Representaciones sociales. Teoría e investigación (pp. 219-253). Guadalajara, México: Universidad de Guadalajara.

Castells, M. (2009). Comunicación y poder. Madrid, España: Alianza Editorial.

Consejo Nacional de Ciencia y Tecnología-CONACYT. (2011). Informe General del estado de la Ciencia y la Tecnología. Recuperado el 11 de noviembre de 2011 de http//:www.conacyt.com.mx

Consejo Nacional para la Cultura y las Artes-CONACULTA. (2006). Encuesta Nacional de Lectura. México: CONACULTA.

Consulta Mitofsky. (2011, diciembre). Perfil de usuario de redes sociales en Internet. Facebook y Twitter. Recuperado el 8 de abril de 2012 de www.consulta.mx

De Garay, S. A. (2001). Los actores desconocidos. Una aproximación al conocimiento de los estudiantes. México: ANUIES.

19 Aunque este concepto también ha causado mucha polémica, ya que para algunos no basta con alfabetizar científicamente a la población, sino lo ideal sería que se apropiaran los usos y sentidos de la ciencia. 
De Garay, S. A. (2004). Integración de los jóvenes en el sistema universitario. Prácticas sociales, académicas y de consumo cultural. México: Ediciones Pomares.

De Garay, S. A. (2006). Las trayectorias educativas en las universidades tecnológicas. Un acercamiento al modelo educativo desde las prácticas escolares de los jóvenes universitarios. Colombia: SEP/UT.

De Garay, S. A. (2009). ¿Y cuatro años después? De cómo los estudiantes de una generación transitan por la universidad. México: Ediciones EÓN/UAM-Azcapotzalco.

Domínguez, S. (2012). Significados de la ciencia en estudiantes universitarios. Aproximaciones a las representaciones sociales de la ciencia, del científico y de la actividad científica. Guadalajara, México: Universidad de Guadalajara.

Domínguez, S. \& Sánchez-Ruiz, E. (2009). Construcciones sociales de la ciencia de acuerdo con alumnos universitarios. En R. Romo (Coord.), Aproximaciones cualitativas a temas de educación. (pp. 145-177). Guadalajara, México: Universidad de Guadalajara/Prometeo Editores.

Dudo, A., Brossard, D., Shanahan, J., Scheufele, D., Morgan, M., \& Signorielli, N. (2011). Science on television in the 21 st century: Recent trends in portrayals and their contributions to public attitudes toward science. Communication Research, 38 (6), 754-777.

Gerbner, G., Gross, L., Morgan, M. \& Signorielli, N. (1981). Scientists on the TV screen. Culture and Society, 42, 51-54.

Gerbner, G., Gross, L., Morgan, M. \& Signorielli, N. (1994). Crecer con la televisión: perspectiva de aculturación. En J. Bryant \& D. Zillman (Comps.), Los efectos de los medios de comunicación. Investigaciones y teorías (pp. 35-66). España: Paidós.

Haro, L., Cabrera, C., Tornero, C., González, C. \& Carrillo, G. (2011, julio/septiembre). Factores sociodemográficos asociados al consumo cultural, del tiempo libre y de medios de comunicación en la educación superior de una universidad pública en Guadalajara. Revista de Educación y Desarrollo, 18, 75-82.

Horrigan, J. B. (2006). The Internet as a resource for news and information about science. Washington, D.C., EE.UU.: Pew Internet \& American Life Project. 
Kalmus, V., Realo, A. \& Siibak, A. (2011). Motives for Internet use and their relationships with personality traits and socio-demographic factors. Trames, 15 (65/60), 385-403.

Márquez, N. \& Tirado, S. (2009, julio). Percepción social de la ciencia y la tecnología de adolescentes mexicanos. Revista Iberoamericana de Ciencia, Tecnología y Sociedad (Portafolio CTS), 2, 16-39.

National Science Foundation. (2012). Science and engineering indicators 2012. Arlington, VA, EE.UU.: National Science Foundation.

Ortiz, H. (2012). L@s jóvenes y su relación con la red Internet: de la adicción al consumo cultural. Razón y Palabra, 78, 1-16.

Research on Social Network Sites. (s.f.). Bibliography of Research on Social Network Sites. Recuperado el 15 de febrero de 2011 de htpp://www.danah.org/researchBibs/sns.php

Sánchez-Ruiz, E. (1994). El público de la prensa. La insoportable levedad de casi no ser. En J. C. Lozano (Ed.), Anuario de Investigación de la Comunicación (pp. 165-186). México: CONEICC.

Sánchez-Ruiz, E. (2005). Medios de comunicación y democracia. Colombia: Grupo Editorial Norma.

The Pew Research Center for the People and the Press. (2011). Internet gains on television as public's main source of news. Recuperado el 15 de febrero de 2011 de http://people-press.org/report/689/

Top Study Links. (2012). Las mejores universidades, colegios en el México 2012. Recuperado el 15 de febrero de 2012 de www.topstudylinks.com

Universia. (2011). Las 10 mejores universidades públicas de México. Recuperado el 15 de febrero de 2012 de www.universia.net.mx.

Universidad de Guadalajara-UdeG. (2012). Numeralia. Recuperado el 30 de septiembre de 2012 de www.udg.mx

UTICA. (2009, 15 de julio). Corrected Version Zogby Poll: Online news sources top all other outlets. Nueva York, EE.UU.: Zogby International. Vogt, C., Morales, A., Righetti, S. \& Caldas, C. (2011). Hábitos informativos sobre ciencia y tecnologia. En C. Polino (Coord.), Los estudiantes y la ciencia: encuesta a jóvenes iberoamericanos (pp. 155-182). Buenos Aires, Argentina: Organización de Estados Iberoamericanos para la Educación, la Ciencia y la Cultura.

Fecha de recepción: 21/06/12. Aceptación: 30/08/12. 